\title{
Risk aversion is associated with decision making among community-based older persons
}

\author{
Patricia A. Boyle ${ }^{1,2 *}$, Lei Yu ${ }^{1,3}$, Aron S. Buchman ${ }^{1,3}$ and David A. Bennett ${ }^{1,3}$ \\ ${ }^{1}$ Rush Alzheimer's Disease Center, Rush University Medical Center, Chicago, IL, USA \\ ${ }^{2}$ Department of Behavioral Sciences, Rush University School of Medicine, Chicago, IL, USA \\ ${ }^{3}$ Department of Neurological Sciences, Rush University School of Medicine, Chicago, IL, USA
}

Edited by:

Sarah F. Brosnan, Georgia State

University, USA

\section{Reviewed by:}

Bernd Weber,

Rheinische-Friedrich-Wilhelms

Universität, Germany

Ann Pearman, Georgia State

University, USA

\section{${ }^{*}$ Correspondence}

Patricia A. Boyle, Rush Alzheimer's Disease Center, Rush Alzheimer's Disease Center, 600 S. Paulina, Suite 1020B, Chicago, IL 60612, USA. e-mail: patricia_boyle@rush.edu

\begin{abstract}
Background: Risk aversion is associated with many important decisions among younger and middle aged persons, but the association of risk aversion with decision making has not been well studied among older persons who face some of the most significant decisions of their lives. Method: Using data from 606 community-dwelling older persons without dementia from the Rush Memory and Aging Project, an ongoing longitudinal epidemiologic study of aging, we examined the association of risk aversion with decision making. Risk aversion was measured using standard behavioral economics questions in which participants were asked to choose between a certain monetary payment $(\$ 15)$ versus a gamble in which they could gain more than $\$ 15$ or gain nothing; potential gamble gains ranged from $\$ 20$ to $\$ 300$ with the gain amounts varied randomly over questions. Decision making was measured using a 12 item version of the Decision Making Competence Assessment Tool. Findings: In a linear regression model adjusted for age, sex, education, and income, greater risk aversion was associated with poorer decision making lestimate $=-1.03$, standard error $(\mathrm{SE})=0.35, p=0.003$ ]. Subsequent analyses showed that the association of risk aversion with decision making persisted after adjustment for global cognitive function as well as executive and non-executive cognitive abilities. Conclusion: Similar to findings from studies of younger persons, risk aversion is associated with poorer decision making among older persons who face a myriad of complex and influential decisions.
\end{abstract}

Keywords: aging, cognition, decision making, risk aversion

\section{INTRODUCTION}

Every day, people make decisions under conditions of uncertainty in a variety of settings (e.g., should I invest in a particular stock? is it safe to cross the street with a car approaching?). Studies from diverse fields including economics, behavioral economics, and psychology have established that risk aversion, the tendency to prefer a certain but possibly less desirable outcome over an uncertain but potentially greater outcome, is predictive of a variety of important decisions including occupational choice, portfolio allocation, healthcare decisions, and even health behaviors (Cohn et al., 1975; Barsky et al., 1997; Donkers and van Soest, 1999; Guiso and Paiella, 2004; Anderson and Mellor, 2008; Hatfield and Fernandes, 2009; Kimball et al., 2009). For example, risk averse persons tend to invest in safe but low yield options such as bonds and choose employment positions with a high likelihood of stability but limited opportunity for advancement, often to the detriment of eventual financial and occupational outcomes (Cramer et al., 2002). By contrast, risk averse persons are less likely to engage in unsafe health behaviors such as cigarette smoking and may have better health outcomes (Anderson and Mellor, 2008; Hatfield and Fernandes, 2009). Notably, although the available data suggest that risk aversion is an important determinant of decision making, most studies have involved relatively young persons and little is known about how risk aversion affects decision making in advanced age. This is an important gap in knowledge given that aging is the time when some of life's most difficult and influential decisions are made (e.g., retirement spending, estate planning, end of life healthcare decisions). Compelling real world indicators such as the selective vulnerability of older persons to fraud and victimization and experimental data suggest that poor decision making is common among older persons, yet the reasons why remain unclear (Denburg et al., 2005; Agarwal et al., 2009). Further, aging is accompanied by changes in cognition, affect and motivation, and it is not known whether the factors related to decision making are the same in older and younger persons (Carstensen et al., 2006). A better understanding of the correlates of decision making is greatly needed to facilitate independence and well being among older persons. The existing literature suggests that risk aversion is an important factor to examine and may represent a target for interventions aimed to improve decision making in advanced age.

In this study, we examined the association of risk aversion with decision making among 606 community-based older adults from the Rush Memory and Aging Project, all of whom were free of dementia (Bennett et al., 2005). Participants underwent assessments of risk aversion using standard behavioral economics questions in which they were asked to choose between a guaranteed payment of $\$ 15$ or a gamble in which they could gain various sums greater than $\$ 15$ or nothing at all. Decision making was examined using a 12 item version of the Decision Making 
Competence Assessment Tool, which uses materials designed to simulate those used in real world settings (Finucane et al., 2005; Finucane and Guillon, 2010). We examined the association of risk aversion with decision making using a linear regression model adjusted for age, sex, education, and income. Further, because we have previously shown that risk aversion is related to cognition, we subsequently examined whether the association of risk aversion with decision making persisted after adjustment for cognition (Boyle et al., 2011).

\section{MATERIALS AND METHODS PARTICIPANTS}

Participants were from the Memory and Aging Project, an ongoing longitudinal study of chronic conditions of aging in the greater Chicago metropolitan area (Bennett et al., 2005). Participation involves risk factor assessment, detailed annual clinical evaluations including medical history, neurological, and neuropsychological examinations. Diagnosis of cognitive impairment and dementia is performed annually using a three stage process, as previously described (Bennett et al., 2005). The study was approved by the Institutional Review Board of Rush University Medical Center, and informed consent and an anatomical gift act were obtained following a detailed presentation of the risks and benefits associated with participation.

Notably, the Memory and Aging Project began in 1997 and enrollment is ongoing. The decision making assessment began in 2010 as part of a substudy that was added and also was approved by the Institutional Review Board of Rush University Medical Center. At the time of these analyses, 1507 participants had completed the baseline evaluation for the parent study; of those, 488 died before participating in the decision making project, and 102 refused further participation in the parent project, leaving 907 potentially eligible persons for decision making assessment. At the time of these analyses, 606 non-demented persons had complete decision making and risk aversion data and were included in the current analyses.

\section{COGNITIVE EVALUATION}

Cognitive function was assessed via a battery of 21 tests, including the MMSE, but MMSE scores were used only to describe the cohort (Bennett et al., 2005). Scores on 19 tests were used to create a summary measure of global cognitive function, as previously described. One additional test, Complex Ideational Material, is used for diagnostic classification purposes only. To compute the composite measure of global cognitive function, raw scores on each of the individual tests were converted to $z$-scores using the baseline mean and standard deviation of the entire cohort, and the $z$-scores of all 19 tests were averaged (Wilson et al., 2005; Boyle et al., 2006). In subsequent analyses, we also examined executive versus nonexecutive measures. For these analyses, we created a composite measure of executive function based on the following tests: two indices from a modified version of the Stroop Neuropsychological Screening Test, Digit Span Forward, Digit Span Backward, Digit Ordering, Symbol Digit Modalities Test, and Number Comparison. All other cognitive tests were considered non-executive (i.e., immediate and delayed recall of story A from Logical Memory, immediate and delayed recall of the East Boston Story, Word List
Memory, Word List Recall, and Word List Recognition, a 15-item version of the Boston Naming Test, Verbal Fluency, a 15-item reading test, a 15-item version of Judgment of Line Orientation, and a 16-item version of Standard Progressive Matrices that included very simple items to assess visuospatial integration). Executive and non-executive cognitive abilities were summarized by averaging $z$-scores of individual tests within each domain.

\section{ASSESSMENT OF RISK AVERSION}

Risk aversion was assessed via a series of 10 questions used in standard behavioral economics approaches as previously described (Boyle et al., 2011; Han et al., 2012). Specifically, participants were asked, "Would you prefer $\$ 15$ for sure, OR a coin toss in which you will get \$ [an amount greater than \$15] if you flip heads or nothing if you flip tails?” Potential gamble gains ranged from $\$ 20.00$ to $\$ 300.00$ with the gain amounts varied randomly across the series of hypothetical questions. When the potential gamble reaches $\$ 30.00$, both the safe payment and the gamble have the same long run average or expected value. However, when the potential gamble gain exceeds $\$ 30$, the expected value of the gamble exceeds the value of the safe payment. Subject specific risk aversion coefficient $\gamma_{i}$ was estimated from these 10 questions, and details of the derivation are presented in the statistical analysis.

\section{ASSESSMENT OF DECISION MAKING}

A 12 item version of the Decision Making Competence Assessment Tool was used to examine healthcare and financial decision making (Finucane et al., 2005; Finucane and Guillon, 2010). This tool was specifically designed to measure decision making in older adults using materials that closely approximate those used in real world settings and has been used in prior studies of aging. Questions focus on health and financial decision making (i.e., HMO plan and mutual fund selection) and vary in difficulty from simple to complex. Simple questions primarily measure decisions that reflect understanding of the information presented. The complex problems parallel the simple problems but involve many more options. For example, one of the simple problems presents information on three mutual funds, including the gross annual return, account management fee, minimum investment, and years of activity, and asks respondents to select the fund with the smallest account management fee. Subsequently, a complex problem presents similar information about seven mutual funds and asks respondents to select the most appropriate fund given pre-specified preferences (e.g., Pamela wants a management fee of less than X\%, a gross annual rate of return of $\mathrm{X} \%$, and a minimum investment of X; which fund should she choose?). The total score is the sum of number of items answered correctly (range $=0-12$ ). In previous research, this measure has been shown to have adequate psychometric properties including high inter-rater reliability and short-term temporal stability, and performance on the measure has been related to cognition and health status (Finucane and Guillon, 2010).

\section{OTHER COVARIATES}

Other variables used in the analyses included age (based on date of birth and date of cognitive testing), sex (females coded as 0 and males as 1), education (years of schooling completed), and income, 
measured using show card methodology, as previously described (Bennett et al., 2005).

\section{STATISTICAL ANALYSIS}

The risk aversion coefficient was estimated using a well-established approach employed in behavioral economics studies in which the index of risk aversion is derived using participants' responses on all 10 risk aversion questions (Barsky et al., 1997; Harrison et al., 2007; Glenn et al., 2008; Boyle et al., 2011; Han et al., 2012). Each question involves a binary choice between a gamble and a safe payoff. If participant $i$ has a constant coefficient of risk aversion $\gamma_{i}$, then the expected utility of the gamble at the $j$ th question, $U_{i j}^{G}$, is defined by the following function,

$$
U_{i j}^{G}=0.5 \times \frac{\operatorname{Gain}_{j}^{1-\gamma_{i}}}{1-\gamma_{i}}
$$

where Gain is $_{j}$ the winning outcome in the $j$ th gamble. Similarly, the safe option payoff for $i$ th participant at $j$ th question has the expected utility

$$
U_{i j}^{S}=\frac{\operatorname{Safe}_{j}{ }^{1-\gamma_{i}}}{1-\gamma_{i}}
$$

where $\mathrm{Safe}_{j}$ is the safe gain for the $j$ th question.

Let observed outcomes in the trials be $Y_{i j}$, and the decision of choosing the gamble be $Y_{i j}=1$; we hypothesized that the probability $P\left(Y_{i j}=1\right)$ depends on the difference between expected utility of the gamble and safe option $U_{i j}^{G}-U_{i j}^{S}$.

The odds of choosing the gamble over safe option therefore was formulated as

$$
\frac{P\left(Y_{i j}=1\right)}{1-P\left(Y_{i j}=1\right)}=e^{U_{i j}^{G}-U_{i j}^{S}}
$$

If $U_{i j}^{G}-U_{i j}^{S}=0$, then a participant was indifferent between the gamble and safe options (i.e., odds of taking the gamble equals to 1 as in $\left.\frac{P\left(Y_{i j}=1\right)}{1-P\left(Y_{i j}=1\right)}=1\right)$, while a positive $U_{i j}^{G}-U_{i j}^{S}$ suggests that a participant favored the gamble (i.e., odds greater than 1), and vice versa. The risk aversion $\gamma_{i}$ was estimated using the above formula.

After computing subject specific risk aversion coefficients, we used linear regression models to investigate whether risk aversion $\gamma_{i}$ was associated with decision making. To do so, we regressed the decision making total score on the risk aversion coefficient $\gamma_{i}$, adjusted for age, sex, education, and income. In a separate model we further adjusted for a term for cognitive function to examine whether the association of risk averse with decision making was mediated by or independent of level of cognitive function. All analyses were implemented in SAS version 9.3 and statistical significance were set at nominal level of $\alpha=0.05$ (SAS Institute Inc, 2009).

\section{RESULTS}

\section{DESCRIPTIVE PROPERTIES OF THE SAMPLE}

Participants in this study $(n=606)$ had a mean age of 82.4 [standard deviation $(\mathrm{SD})=7.5$, range 59.4-100.8], and the mean education was 15.2 years $(\mathrm{SD}=3.0$, range $7-28)$. Four hundred sixty-three subjects $(76.4 \%)$ were female. Twenty-seven percentage reported annual income lower than $\$ 25 \mathrm{~K}, 36 \%$ had income between $\$ 25$ and $\$ 50 \mathrm{~K}$, and $37 \%$ had income over $50 \mathrm{~K}$. The mean level of cognitive function was 0.2 standard unit $(\mathrm{SD}=0.5$, range $-1.4-1.6)$, with higher scores indicating better cognition. The mean decision making total score was $7.5(\mathrm{SD}=2.9$, range $0-12)$, with higher scores indicating better decision making. The mean estimate of risk aversion derived from participants' responses to all risk aversion questions was $0.3(\mathrm{SD}=0.3$; range, $0.06-0.9)$, with higher values indicating greater risk aversion.

\section{BIVARIATE ASSOCIATIONS OF RISK AVERSION AND OTHER VARIABLES WITH DECISION MAKING}

Because risk aversion has rarely been studied among older persons, we first conducted analyses examining the bivariate associations of risk aversion and the demographic factors with decision making (Table 1). Risk aversion and age were negatively associated with decision making, such that greater risk aversion and older age were associated with poorer decision making. By contrast, education, male sex, income, and global cognition were positively associated with decision making (means for men and women were 8.3 and 7.3, respectively; $t=-4.4, \mathrm{df}=277.3, p<0.001)$. Intercorrelations among all study variables also are presented in the Table.

\section{RELATION OF RISK AVERSION WITH DECISION MAKING}

To test the hypothesis that risk aversion was associated with the level of decision making, we constructed a linear regression model with the decision making total score as the outcome and terms for the coefficient of risk aversion $\gamma_{i}$, age, sex, education, and income. The results of this analysis (Table 2) showed that older age, fewer years of education and lower income were all associated with poorer decision making ( $p$ 's $<0.001)$, and males performed relatively better than female participants $(p=0.04)$. Controlling for age, sex, education, and income, greater risk aversion was associated with poorer decision making (Estimate $=-1.03, \mathrm{SE}=0.35$, $p=0.003)$. To clarify this effect, the average decision making score was reduced by about 0.3 unit when the coefficient of risk aversion increased by 1 standard deviation. This was equivalent to the effect of being about three additional years older.

Next, because prior literature has shown that risk aversion is highly associated with level of cognitive function and we have reported the same association in this cohort, we repeated the previous model after adding in a term for global cognitive function to examine whether the association of risk aversion with decision making was independent of or mediated by cognition (Dohmen et al., 2010; Boyle et al., 2011). As expected, in this analysis, a higher level of cognition was strongly associated with better decision making (Estimate $=2.44, \mathrm{SE}=0.19, p<0.001$ ). Further, the association between risk aversion and decision making persisted but was somewhat attenuated $(p=0.022)$ after adjustment for global cognition, suggesting partial mediation.

Finally, because it is possible that combining all of the cognitive tests into a single measure could obscure the effects of particular cognitive abilities and prior studies suggest that executive functions are related to risk aversion as well as decision making, 
Table 1 | Inter-correlations among study variables*.

\begin{tabular}{|c|c|c|c|c|c|c|}
\hline Variable $r, p$-value & Education & Sex & Income & Global cognition & Risk aversion & Decision making \\
\hline Age & $-0.07,0.079$ & $0.05,0.200$ & $-0.04,0.328$ & $-0.32,<0.001$ & $0.09,0.024$ & $-0.30,<0.001$ \\
\hline Education & & $0.19,<0.001$ & $0.40,<0.001$ & $0.33,<0.001$ & $-0.13,0.001$ & $0.40,<0.001$ \\
\hline Income & & & & $0.26,<0.001$ & $-0.18,<0.001$ & $0.34,<0.001$ \\
\hline Global cognition & & & & & $-0.12,0.002$ & $0.59,<0.001$ \\
\hline
\end{tabular}

*Based on Spearman correlations.

Table 2 | Associations of risk aversion with decision making.

\begin{tabular}{lll}
\hline Parameter & Estimate (SE), Pr $>|\boldsymbol{t}|$ & Estimate $(\mathrm{SE}), \operatorname{Pr}>|\boldsymbol{t}|$ \\
\hline Age & $-0.12(0.01),<0.001$ & $-0.07(0.01),<0.001$ \\
Education & $0.22(0.04),<0.001$ & $0.11(0.03),<0.001$ \\
Male sex & $0.50(0.24), 0.041$ & $0.82(0.22),<0.001$ \\
Income & $0.24(0.05),<0.001$ & $0.13(0.04), 0.001$ \\
Cognition & - & $2.44(0.19),<0.001$ \\
Risk aversion & $-1.03(0.35), 0.003$ & $-0.71(0.31), 0.022$
\end{tabular}

we next examined whether the association of risk aversion with decision making persisted in separate models adjusted for executive and non-executive cognitive abilities, respectively (Brand et al., 2008; Brand and Markowitsch, 2010). The association of risk aversion with decision making persisted after adjustment for executive abilities in the first model (Estimate for risk aversion $=-0.66, \mathrm{SE}=0.31, p=0.036$ ) and after adjustment for nonexecutive cognitive abilities in the second model (Estimate for risk aversion $=-0.83, \mathrm{SE}=0.32, p=0.010$ ) but was somewhat attenuated in both models (as in the model adjusted for global cognitive function).

\section{DISCUSSION}

In a cohort of 606 community-based older persons free of dementia, we found that risk aversion was associated with poorer decision making. Further, the association of risk aversion with decision making persisted after adjustment for cognitive function, including global cognition and executive cognitive abilities. These findings are the first that we are aware of addressing the relation of risk aversion and decision making among older persons and suggest that risk aversion is an important determinant of decision making in advanced age as it is at younger ages. This finding may have important implications for improving decision making and ultimately health and well being among older persons.

Risk preferences have long been the focus of economics and behavioral economics studies and have established relevance for economic and health decisions and outcomes (Anderson and Mellor, 2008; Agarwal et al., 2009; Hatfield and Fernandes, 2009). The literature on risk aversion in aging consists primarily of studies examining whether older persons are more or less risk averse than younger persons. Findings are mixed, however, and appear to vary depending on task characteristics, learning requirements, and modeling approaches (Deakin et al., 2004; Agarwal et al., 2009; Samanez-Larkin et al., 2010; Mata et al., 2011). For example, in a recent study that used a computer-based, experimental measure of risk aversion, analyses of participants' overall performance suggested no age differences (Rolison et al., 2012); however, subsequent analyses examining response patterns indicated that younger persons were initially more likely to take greater risks, whereas older persons were more risk averse when making decisions based on early perceptions of risk (compared to when making decisions after learning from task-based experience). Another study used a gambling task and found no age difference in risk aversion when options were presented in a gain frame (e.g., “keep $\$ 20$ of $\$ 100$ "), but younger adults were more risk seeking when options were presented in a loss frame (e.g., "lose $\$ 80$ of \$100"; Mikels and Reed, 2009). It is thought that age-related changes in motivation and affect may contribute to the observed differences, but additional research is needed to further clarify such age differences as well as to better understand their basis (Carstensen et al., 2006).

Notably, the present study extends prior work by studying an important behavioral correlate of risk aversion, decision making, in a well-characterized sample of non-demented older persons. The relation of risk aversion with decision making is wellestablished among younger persons and examination of this association among older persons is important in light of the fact that aging is a time when many difficult, risky, and consequential decisions are made. Further, older persons have limited opportunities to recover from errors in decision making due in part to shortened time horizons and age-related changes in cognition and other personal resources. From real world indicators such as the selective vulnerability of older persons to financial and other forms of fraud to experimental data, mounting evidence suggests that older persons frequently make suboptimal decisions (Denburg et al., 2005; Agarwal et al., 2009). Understanding the correlates of decision making in advanced age offers the potential to facilitate efforts to improve decision making and health and well being among older persons. The present findings are consistent with data from younger persons and suggest that risk aversion is negatively associated with decision making among older persons just as it among younger persons. Thus, persons of all ages may benefit from assistance in understanding risk/benefit ratios and the importance of considering all possible options and outcomes, not just the safe choice, when making decisions.

Importantly, in this study, the association between risk aversion and decision making persisted after adjustment for global cognitive function, although it was somewhat attenuated, suggesting 
partial mediation. The relation of risk aversion with decision making also persisted but was somewhat attenuated in analyses adjusted for executive cognitive abilities as well as non-executive cognitive abilities. Cognitive function, particularly executive function, is one of the few factors known to influence decision making in aging, particularly decisions involving multiple choices and risky decision making (Brand et al., 2007, 2008; Brand and Markowitsch, 2010; Finucane and Guillon, 2010; Henninger et al., 2010). Cognition also has been shown to be a strong determinant of risk aversion in younger persons, and we previously reported an association between cognition and risk aversion among older persons from this cohort (Dohmen et al., 2010; Boyle et al., 2011). That the association of risk aversion with decision making persisted after controlling for global cognition as well as executive cognitive abilities suggests that decision making is a complex function of many characteristics and factors other than cognition may be important determinants of decision making in aging. Although speculative, given the sensitive nature of the decisions older persons make and the common occurrence of cognitive decline in old age, it is possible that non-cognitive factors may be salient determinants of decision making near the end of life. Personality traits such as neuroticism and openness to experience are related to risk taking (Lauriola and Levin, 2001), and recent data suggest that higher levels of neuroticism are associated with poor reasoning and decision making under conditions of uncertainty among older but not younger persons (Denburg et al., 2009); the latter findings may suggest that stress negatively impacts cognitive function and consequently decision making at older ages specifically. Taken together, these findings suggest that a focus on personality characteristics or other psychological features of the decision

\section{REFERENCES}

Agarwal, S., Driscoll, J. C., Gabaix, X., and Laibson, D. (2009). The age of reason: financial decisions over the life-cycle and implications for regulation. Brookings Pap. Econ. Act. 2, 51-117.

Anderson, L. R., and Mellor, J. M. (2008). Predicting health behaviors with an experimental measure of risk preference. J. Health Econ. 27, 1260-1274.

Barsky, B., Juster, F. T., Kimball, M., and Shapiro, M. (1997). Preference parameters and behavioral heterogeneity: an experimental approach in the Health and Retirement Study. Q. J. Econ. 112, 537-579.

Bennett, D. A., Schneider, J. A., Buchman, A. S., Mendes de Leon, C., Bienais, J. L., and Wilson, R. S. (2005). The Rush Memory and Aging Project: study design and baseline characteristics of the study cohort. Neuroepidemiology 25, 163-175.

Boyle, P. A., Wilson, R. S., Aggarwal, N. T., Tang, Y., and Bennett, D. A. (2006). Mild cognitive impairment: risk of Alzheimer disease and rate of cognitive decline. Neurology 67, 441-445.

Boyle, P. A., Yu, L., Buchman, A. S., Laibson, D. I., and Bennett, D. A. (2011). Cognitive function is associated with risk aversion in community-based older persons. BMC Geriatr. 11, 53. doi:10.1186/1471-2318-11-53

Brand, M., and Markowitsch, H. J. (2010). Aging and decision-making: a neurocognitive perspective. Gerontology 56, 319-324.

Brand, M., Recknor, E. C., Grabenhorst, F., and Bechara, A. (2007). Decisions under ambiguity and decisions under risk: correlations with executive functions and comparisons of two different gambling tasks with implicit and explicit rules. J. Clin. Exp. Neuropsychol. 29, 86-99.

Brand, M., Roth-Bauer, M. R., Driessen, M., and Markowitsch, H. J. (2008). Executive functions and risky decision making in patients with opiate dependence. Drug Alcohol Depend. 97, 64-72.

Carstensen, L. L., Mikels, J. A., and Mather, M. (2006). "Aging and the intersection of cognition, motivation, and emotion," in Handbook of

maker may help to elucidate the factors that contribute to poor decision making in old age.

This study has a number of strengths, including the assessment of risk aversion using questions used in behavioral economics studies in a well-characterized cohort of older persons free of dementia and detailed assessment of cognition based on 19 cognitive tests in a fairly large cohort of community-dwelling older adults. A limitation of the study is the selected nature of this volunteer cohort, which may have restricted our range of risk aversion and may limit the generalizability of findings. Another limitation was the assessment of risk aversion and decision making at a single point in time (rather than measuring change over time). Future studies are needed to investigate potential age-related changes in risk aversion and decision making, and to examine the predictive association of risk aversion with adverse health outcomes in advanced age. Ultimately, these studies will inform on the extent to which risk aversion impacts real world outcomes across the lifespan.

\section{ACKNOWLEDGMENTS}

We are indebted to the participants and the staff of the Rush Memory and Aging Project and the Rush Alzheimer's Disease Center for this work, and to Woojeong Bang for statistical programming. The study was supported by NIA grants R01AG17917, R21AG30765, R01AG34374, and R01AG33678; the funding agency was not involved in the design, analysis, or interpretation of these data or preparation of the manuscript. Dr. Boyle had full access to all of the data in the study and takes responsibility for the integrity of the data and the accuracy of the data analysis.

the Psychology of Aging, 6th Edn, eds J Birren and K. W. Schai (San Diego: Academic Press), 343-363.

Cohn, R. A., Lewellen, W. G., Lease, R. C., and Scharbaum, G. G. (1975). Individual investor risk aversion and investment portfolio composition. J. Finance 30, 605-620.

Cramer, A., Hartog, J., Jonker, N., and VanPragg, C. M. (2002). Low risk aversion encourages the choice for entrepreneurship: an empirical test of a truism. J. Econ. Behav. Organ. 48, 29-36.

Deakin, J., Aitken, M., Robbins, T., and Sahakian, B. J. (2004). Risk taking during decision-making in normal volunteers changes with age. J. Int. Neuropsychol. Soc. 10, 590-598.

Denburg, N., Tranel, D., and Bechara, A. (2005). The ability to decide advantageously declines prematurely in some normal older persons. $\mathrm{Neu}$ ropsychologia 7, 1099-1106.

Denburg, N., Weller, J. A., Yamada, T. H., Shivapour, D. M., Kaup, A. R., LaLoggia, A., Cole, C. A., Tranel, D., and Bechara, A. (2009). Poor decision making among older adults is related to elevated levels of neuroticism. Ann. Behav. Med. 37, 64-172.
Dohmen, T., Falk, A., Huffman, D., and Sundwm, U. (2010). Are risk aversion and impatience related to cognitive ability? Am. Econ. Rev. 100, 1238-1260.

Donkers, B., and van Soest, A. (1999). Subjective measures of household preferences and financial decisions. J. Econ. Psychol. 6, 613-642.

Finucane, M. D., Mertz, C. K., Slovik, P., and Schmidt, E. S. (2005). Task complexity and older adults' decision making competence. Psychol. Aging 1, 71-84.

Finucane, M. L., and Guillon, C. M. (2010). Developing a tool for measuring the decision making competence of older adults. Psychol. Aging 2, 271-288.

Glenn, W., Harrison, E., and Rutström, E. (2008). "Risk aversion in the laboratory," in Risk Aversion in Experiments (Research in Experimental Economics, Vol. 12), eds J. C. Cox and G. W. Harrison (Wagon Lane: Emerald Group Publishing Limited), 41-196.

Guiso, L., and Paiella, M. (2004). The Role of Risk Aversion in Explaining Individual Behaviors. CEPR Discussion Paper No. 4591, Rome. 
Han, S. D., Boyle, P. A., Arfanakis, K., Fleischman, D. A., Yu, L., Edmonds, E. C., and Bennett, D. A. (2012). Neural intrinsic connectivity networks associated with risk aversion in old age. Behav. Brain Res. 227, 233-240.

Harrison, G. W., List, J. A., and Town, C. (2007). Naturally occurring preference and exogenous laboratory experiments: a case study of risk aversion. Econometrika 2, 433-458.

Hatfield, J., and Fernandes, R. (2009). The role of risk-propensity in the risky driving of younger drivers. Accid. Anal. Prev. 41, 25-35.

Henninger, D. E., Madden, D. J., and Huettel, S. A. (2010). Processing speed and memory mediate age related differences in decision making. Psychol. Aging 25, 262-270.
Kimball, M., Sahm, C., and Shapiro, M. (2009). Risk preferences in the PSID: individual imputations and family covariation. Am. Econ. Rev. 99, 363-368.

Lauriola, M., and Levin, I. P. (2001). Personality traits and risky decision making in a controlled task: an exploratory study. Pers. Individ. Dif. 312, 215-226.

Mata, R., Josef, A. K., Samanez-Larkin, G. R., and Hertwig, R. (2011). Age differences in risky choice: a metaanalysis. Ann. N. Y. Acad. Sci. 1235, 18-29.

Mikels, J. A., and Reed, A. E. (2009). Monetary losses do not loom large in later life: age differences in the framing effect. J. Gerontol. B Psychol. Sci. Soc. Sci. 4, 457-460.

Rolison, J. J., Hanoch, Y., and Wood, S. (2012). Risky decision making in younger and older adults: the role of learning. Psychol. Aging 27, 129-140.

Samanez-Larkin, G. R., Kuhnen, C. M. Yoo, D. J., and Knutson, B. (2010). Variability in nucleus accumbens activity mediates age-related suboptimal financial risk taking. J. Neurosci. 30, 1426-1434.

SAS Institute Inc. (2009). SAS/STAT User's Guide, Version 9. 3. Cary, NC: SAS Institute Inc.

Wilson, R. S., Barnes, L. L., Krueger K. R., Hoganson, G., Bienias, J. L., and Bennett, D. A. (2005). Early and late-life cognitive activity and cognitive systems in old age. J. Int. Neuropsychol. Soc. 11, 400-407.

Conflict of Interest Statement: The authors declare that the research was conducted in the absence of any commercial or financial relationships that could be construed as a potential conflict of interest.

Received: 05 March 2012; accepted: 01 June 2012; published online: 28 June 2012.

Citation: Boyle PA, Yu L, Buchman AS and Bennett DA (2012) Risk aversion is associated with decision making among community-based older persons. Front. Psychology 3:205. doi: 10.3389/fpsyg.2012.00205

This article was submitted to Frontiers in Decision Neuroscience, a specialty of Frontiers in Psychology.

Copyright $\odot 2012$ Boyle, Yu, Buchman and Bennett. This is an open-access article distributed under the terms of the Creative Commons Attribution Non Commercial License, which permits noncommercial use, distribution, and reproduction in other forums, provided the original authors and source are credited. 